\title{
H $\infty$ Optimization of Tuned Inerter Damper with Negative Stiffness Device Subjected to Support Excitation
}

\author{
Kun Ye and Patrice Nyangi iD \\ School of Civil Engineering and Mechanics, Huazhong University of Science and Technology, Wuhan 430074, China \\ Correspondence should be addressed to Patrice Nyangi; patricenyangi@hust.edu.cn
}

Received 23 December 2019; Revised 9 October 2020; Accepted 24 October 2020; Published 1 December 2020

Academic Editor: Andrea Spaggiari

Copyright ( 2020 Kun Ye and Patrice Nyangi. This is an open access article distributed under the Creative Commons Attribution License, which permits unrestricted use, distribution, and reproduction in any medium, provided the original work is properly cited.

In this study, $\mathrm{H}_{\infty}$ optimization is conducted for a tuned inerter damper (TID) with negative stiffness device (denoted as TID_NSD) subjected to harmonic support excitation. The study shows that there are still two nonzero-frequency fixed points independent of the damping of the TID_NSD; therefore, the optimum tuning frequency and damping ratio for the TID_NSD are, respectively, derived based on the well-known fixed points theory. By imposing the zero-frequency fixed point having the same amplitude as the other two nonzero-frequency fixed points, the optimum negative stiffness ratio, which makes the primary system with a TID_NSD remain stable, is obtained. Moreover, the role of a negative stiffness device of a TID_NSD system in response control of a single degree-of-freedom (SDOF) structure is evaluated through parametric study. Also, a numerical analysis is conducted on both a SDOF and multiple DOFs structure to validate the feasibility of the derived formulas by simulations with real earthquake records. Numerical results demonstrate that the maximum displacement and the maximum absolute acceleration of the structure equipped with TID_NSD system are reduced by increasing the absolute value of negative stiffness ratio. The results also show that the optimally designed TID_NSD system outperforms the optimally designed TID system in terms of the displacement and absolute acceleration mitigation control. The closed-form solutions proposed in this study can be useful for the optimal design of the structure equipped with TID_NSD.

\section{Introduction}

The tuned mass damper (TMD) is a handy passive device and widely used in the domain of vibration control. And the fixed points theory was established to derive the optimum tuning frequency and damping ratio of TMD in terms of $\mathrm{H}_{\infty}$ optimization [1]. Recently, the inerter, a new passive mechanical element, was proposed by Smith in order to complete the force-current analogy between mechanical and electrical elements [2]. As a two-terminal device, inerter has the property that the resisting force applied at its two terminals is proportional to the relative acceleration between them. And this constant of proportionality is defined as the inertance with a unit of a kilogram. Since the initial application in Formula One racing car suspension systems [3], inerters have been successfully applied to other mechanical systems, such as vehicle suspensions [4-6], motorcycle steering systems [7], and train suspension [8, 9]. There are various ways of mechanical realization of inerters such as the rack-and-pinion mechanisms [2], ball-screw mechanisms [10], electromagnetic devices [11], hydraulic devices [12, 13], and inerter with a clutch [14]. By using the realizations above, an elaborately designed inerter can provide higher mass ratios required by TMD. Therefore, several tuned inerter-based dampers, namely, viscous mass damper (VMD) and tuned viscous mass damper (TVMD) $[15,16]$, tuned inerter damper (TID) [17], tuned mass-damperinerter system (TMDI) [18-20], and multituned mass damper inerter (MTMDI) [21], have been theoretically investigated and numerically verified based on the concept of TMD with mass replaced partly or entirely by inerter.

Moreover, the idea of introducing a negative stiffness device for vibration control has been investigated and verified to have a better vibration control performance; see, 
for example, [22-32]. Unlike a conventional positive stiffness element that resists the motion, a negative stiffness device exerts the force that supports the motion of a structure [22, 23, 25]. In their study, Wang and Lakes [30] analyzed several spring systems' stability with a negative stiffness device. Zhou et al. [31] proposed and analyzed a quasi-zero-stiffness (QZS) strut with a negative-stiffness mechanism. Wang et al. [29] analytically investigated the use of a negative stiffness device and inerter for enhancing the performance of dynamic vibration absorber (DVA). The detailed results revealed superior performance in reducing the peak amplitude frequency of the primary system and broadening the frequency range of vibration suppression. To control the seismic response of a single-degree-of-freedom (SDOF) systems, Wang et al. [28] suggested a negative stiffness amplifying damper (NSAD). It was concluded that introducing a negative stiffness device to the SDOF system could substantially decrease both displacement and acceleration responses. Using the stability maximization criterion (SMC) and the fixed-points theory, Zhou et al. [32] derived analytical solutions for the optimal parameters of DVAs with a negative stiffness device. After conducting numerical simulations under harmonic excitation, it was demonstrated that the incorporation of a negative stiffness device could be beneficial in reducing the maximum vibration amplitude and the stroke length in addition to increasing the frequency range of vibration suppression. Another study conducted by Saha and Misra [24] examined the feasibility of employing the nonconventional TMD adopting an adaptive negative stiffness device (ANSD) for seismic control of vulnerable tall buildings. Shi et al. [26] conducted a comparative study to reveal the similarity and differences between a negative stiffness device and an inerter in the vibration control application. The related results indicated that both a negative stiffness device and an inerter could efficiently decrease the Ho norm. Moreover, it was revealed that the negative stiffness device could also decrease the $\mathrm{H} 2$ norm, whereas the $\mathrm{H} 2$ norm could not converge under the effect of inerter. Their findings supported the reason why a TID is more commonly adopted in vibration control systems.

It can be noted from the above-reported research works that the use of inerter, negative stiffness device, or inerter and negative stiffness concurrently could improve the performance of DVAs. However, to the best of the authors' knowledge, the optimal design and performance benefits of DVAs with a dual combination between inerter and negative stiffness device have not been widely investigated. Therefore, this study presents a detailed analytical and numerical investigation of a TID with a negative stiffness device (denoted as TID_NSD). First, an Ho optimization is conducted to minimize the resonant vibration amplitude of a SDOF system under harmonic ground excitation. Based on the well-known fixed points theory, the closed-form solutions of the optimum parameters of the TID_NSD are then presented. Moreover, the effect of a negative stiffness device on the seismic response control of the TID system is investigated through a parametric analysis. Also, the effectiveness of the derived design formulas is validated through numerical simulation with 20 real earthquake records. Finally, a numerical application is provided in which a TID_NSD system is installed in a case study building.

\section{Mechanical Model and Equations of Motion of TID_NSD}

The analytical mechanical model of the TID_NSD mounted on an undamped primary system is shown in Figure 1, where the primary system is simplified as a lumped mass $m_{\mathrm{P}}$ with stiffness $k_{\mathrm{P}}$. The TID_NSD is shown as an inerter with inertance $m_{\mathrm{I}}$, stiffness $k_{\mathrm{TID}}$, damping $\mathcal{c}_{\mathrm{TID}}$, and negative stiffness $k_{\mathrm{N}}$.

A schematic representation for the physical realization of the TID_NSD is shown in Figure 2, where an inerter and a negative stiffness device (NSD) are connected in parallel to form a subsystem, which is then conjoined in series with another subsystem of a spring element and dashpot element in parallel. For the construction of the TID_NSD, a ballscrew inerter [15] and a negative stiffness device [23] are recommended.

Although the negative stiffness device mainly exhibits geometrical nonlinearity, the negative stiffness device, if properly designed, is approximately linear in a given displacement range [31]. Therefore, for convenience of analytical derivation, the force-displacement relationship of the negative stiffness device is assumed to be linear in this study, which was also adopted by some research works on the negative stiffness device $[22,33]$. Let $u_{\mathrm{P}}$ represent the displacement of the primary mass relative to the ground and $u_{\mathrm{I}}$ be that of the TID_NSD. The equation of motion for the entire system excited by the support acceleration $a_{\mathrm{g}}$ can be expressed as

$$
\begin{aligned}
& {\left[\begin{array}{cc}
m_{\mathrm{P}} & 0 \\
0 & m_{\mathrm{I}}
\end{array}\right]\left\{\ddot{u}_{\mathrm{P}} \ddot{u}_{\mathrm{I}}\right\}+\left[\begin{array}{cc}
c_{\mathrm{TID}} & -c_{\mathrm{TID}} \\
-c_{\mathrm{TID}} & c_{\mathrm{TID}}
\end{array}\right]\left\{\begin{array}{c}
\dot{u}_{\mathrm{P}} \\
\dot{u}_{\mathrm{I}}
\end{array}\right\}} \\
& +\left[\begin{array}{cc}
k_{\mathrm{P}}+k_{\mathrm{TID}} & -k_{\mathrm{TID}} \\
-k_{\mathrm{TID}} & k_{\mathrm{TID}}+k_{\mathrm{N}}
\end{array}\right]\left\{\begin{array}{c}
u_{\mathrm{P}} \\
u_{\mathrm{I}}
\end{array}\right\}=-\left\{\begin{array}{c}
m_{\mathrm{P}} \\
0
\end{array}\right\} a_{\mathrm{g}} .
\end{aligned}
$$

Define the following parameter transformation:

$$
\begin{aligned}
\omega_{P} & =\sqrt{\frac{k_{P}}{m_{P}}}, \\
\omega_{\mathrm{TID}} & =\sqrt{\frac{k_{\mathrm{TID}}}{m_{I}}}, \\
\lambda_{T} & =\frac{c_{\mathrm{TID}}}{2 m_{I} \omega_{\mathrm{TID}}}, \\
\mu & =\frac{m_{I}}{m_{P}}, \\
\beta & =\frac{\omega_{\mathrm{TID}}}{\omega_{P}}, \\
\theta & =\frac{k_{N}}{k_{\mathrm{TID}}} .
\end{aligned}
$$




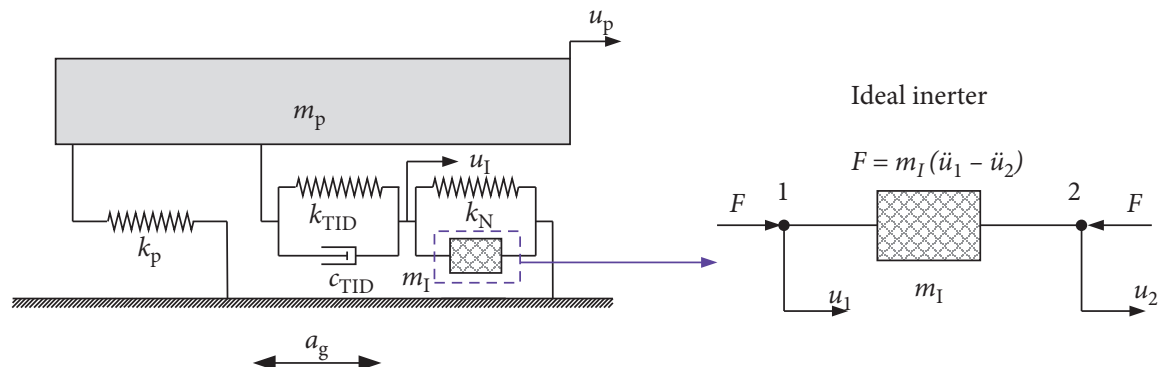

FIgURE 1: Analytical mechanical model of TID_NSD under harmonic support excitation with fixed-acceleration amplitude.

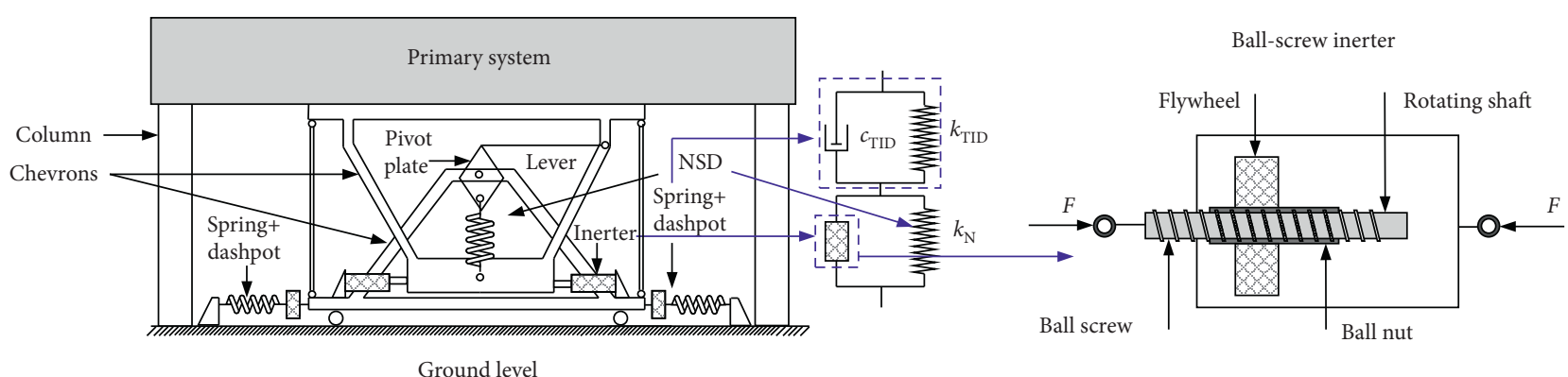

FIGURE 2: Schematic representation for the physical realization of TID_NSD.

Equation (1) can be rewritten as

$$
\begin{aligned}
& {\left[\begin{array}{ll}
1 & 0 \\
0 & \mu
\end{array}\right]\left\{\ddot{u}_{P} \ddot{u}_{I}\right\}+\left[\begin{array}{cc}
2 \mu \beta \lambda \omega_{p} & -2 \mu \beta \lambda \omega_{p} \\
-2 \mu \beta \lambda \omega_{p} & 2 \mu \beta \lambda \omega_{p}
\end{array}\right]\left\{\begin{array}{l}
\dot{u}_{P} \\
\dot{u}_{I}
\end{array}\right\}} \\
& +\left[\begin{array}{cc}
\left(1+\mu \beta^{2}\right) \omega_{p}^{2} & -\mu \beta^{2} \omega_{p}^{2} \\
-\mu \beta^{2} \omega_{p}^{2} & (1+\theta) \mu \beta^{2} \omega_{p}^{2}
\end{array}\right]\left\{\begin{array}{l}
u_{P} \\
u_{I}
\end{array}\right\}=-\left\{\begin{array}{l}
1 \\
0
\end{array}\right\} a_{g},
\end{aligned}
$$

where $\omega_{\mathrm{P}}$ and $\omega_{\mathrm{T}}$ are the natural frequencies of the primary mass and the TID_NSD, respectively, and $\lambda_{\mathrm{P}}$ and $\lambda_{\mathrm{T}}$ are their associated damping ratios. $\mu$ is the ratio of the damper mass to the primary mass. $\beta$ denotes the nondimensional tuning frequency ratio, and $\theta$ represents the negative stiffness ratio of the TID_NSD. When the support excitation is harmonic, and its acceleration amplitude is fixed and independent of frequency; that is, $a_{\mathrm{g}}=A_{\mathrm{g}} e^{i \omega t}$; the steady-state response of the system can be solved from

$$
\left[\begin{array}{cc}
-\omega^{2}+2 i \mu \beta \lambda \omega_{P} \omega+\left(1+\mu \beta^{2}\right) \omega_{P}^{2} & -2 i \mu \beta \lambda \omega_{P} \omega-\mu \beta^{2} \omega_{P}^{2} \\
-2 i \mu \beta \lambda \omega_{P} \omega-\mu \beta^{2} \omega_{P}^{2} & -\mu \omega^{2}+2 i \mu \beta \lambda \omega_{P} \omega+(1+\theta) \mu \beta^{2} \omega_{P}^{2}
\end{array}\right]\left\{\begin{array}{l}
u_{P} \\
u_{I}
\end{array}\right\}=-\left\{\begin{array}{l}
1 \\
0
\end{array}\right\} A_{g} e^{i \omega t} .
$$

Thus, the dynamic amplification factor (DAF), defined as the ratio of vibration amplitude of the main mass to the input amplitude, can be solved as

$$
\mathrm{DAF}=\frac{\omega_{\mathrm{P}}^{2}\left|u_{\mathrm{P}}\right|}{A_{\mathrm{g}}}=\sqrt{\frac{\left[(1+\theta) \beta^{2}-\gamma^{2}\right]^{2}+(2 \lambda \beta \gamma)^{2}}{\left[\gamma^{4}-\left(1+\beta^{2}+\mu \beta^{2}+\theta \beta^{2}\right) \gamma^{2}+(1+\theta) \beta^{2}+\mu \theta \beta^{4}\right]^{2}+\left[2 \lambda \beta \gamma\left(1+\mu \theta \beta^{2}-(1+\mu) \gamma^{2}\right)\right]^{2}}},
$$

where $\gamma=\omega / \omega_{\mathrm{P}}$ represents the ratio of the exciting frequency of ground motion to the primary fundamental frequency. The above equation is a function of the parameters $\mu, \beta, \lambda$, and $\theta$. Changing these parameters can affect the value of DAF. Let $\Gamma$ denote $\gamma^{2}$, and the above equation can then be rewritten as 


$$
|\mathrm{DAF}|^{2}=\frac{\left[(1+\theta) \beta^{2}-\Gamma\right]^{2}+(2 \lambda \beta)^{2} \Gamma}{\left[\Gamma^{2}-\left(1+\beta^{2}+\mu \beta^{2}+\theta \beta^{2}\right) \Gamma+(1+\theta) \beta^{2}+\mu \theta \beta^{4}\right]^{2}+\left[2 \lambda \beta\left(1+\mu \theta \beta^{2}-(1+\mu) \Gamma\right)\right]^{2} \Gamma} .
$$

Furthermore, in order to sustain the stability of the entire system due to the introduction of negative stiffness device, the stability requirement is that the overall static stiffness of the system should be positive; that is,

$$
k=k_{\mathrm{P}}+\frac{k_{\mathrm{TID}} k_{\mathrm{N}}}{k_{\mathrm{TID}}+k_{\mathrm{N}}}>0
$$

By the use of the notations defined in (2), the aforementioned stability requirement in terms of $\theta$ is written as

$$
\theta_{\text {Allowable }}=-\frac{1}{1+\mu \beta^{2}}<\theta<0 .
$$

Alternatively, in terms of $\beta$, the stability requirement is also written as

$$
\beta<\beta_{\text {Allowable }}=\sqrt{-\left(\frac{1+\theta}{\mu \theta}\right)} .
$$

\section{H $\infty$ Optimization of TID_NSD Based on the Fixed Points Theory}

For a given mass ratio $\mu$, the objective of $\mathrm{H}_{\infty}$ optimization of TID_NSD is to determine three design variables $\beta, \lambda$, and $\theta$ that minimize the $\mathrm{H}_{\infty}$ norm (i.e., the maximum of DAF in Equation (5)), which is mathematically formulated as follows:

$$
\min \left(\max _{\beta, \lambda, \theta} \operatorname{DAF}(\gamma)\right)
$$

For given $\beta, \lambda$, and $\theta$, the value of DAF can be calculated based on equation (5). In Figure 3, the results under $\mu=1.0$, $\beta=1.1$, and $\theta=-0.2$ are shown. At the same time, the results in several cases of damping ratios are also given in this figure. It is clearly seen that there exist two common points (i.e., $\mathrm{P}$ and Q) on all the curves, where the values of DAF are not affected by the damping ratio. These points are referred to as fixed points. Therefore, the optimum parameters of the TID_NSD could be determined by use of the well-known fixed points theory [1].
In the proceeding, the fixed points theory will be utilized to derive the optimum design parameters of the TID_NSD under study. It can be proved that equation (5) can be rewritten in the form

$$
\mathrm{DAF}=\sqrt{\frac{A+B \lambda^{2}}{C+D \lambda^{2}}},
$$

where

$$
\begin{aligned}
& A=\left[(1+\theta) \beta^{2}-\gamma^{2}\right]^{2}, \\
& B=(2 \beta \gamma)^{2}, \\
& C=\left[\gamma^{4}-\left(1+\beta^{2}+\mu \beta^{2}+\theta \beta^{2}\right) \gamma^{2}+(1+\theta) \beta^{2}+\mu \theta \beta^{4}\right]^{2}, \\
& D=\left[2 \beta \gamma\left(1+\mu \theta \beta^{2}-(1+\mu) \gamma^{2}\right)\right]^{2} .
\end{aligned}
$$

According to the fixed points theory, the fixed points are independent of $\lambda$. Therefore, at the fixed points $P$ and $Q$, the condition $A / C=B / D$ should be satisfied; that is,

$$
\begin{gathered}
\frac{(1+\theta) \beta^{2}-\gamma^{2}}{\gamma^{4}-\left(1+\beta^{2}+\mu \beta^{2}+\theta \beta^{2}\right) \gamma^{2}+(1+\theta) \beta^{2}+\mu \theta \beta^{4}} \\
= \pm\left[\frac{2 \beta \gamma}{2 \beta \gamma\left(1+\mu \theta \beta^{2}-(1+\mu) \gamma^{2}\right)}\right] .
\end{gathered}
$$

The plus sign in the above equation gives a trivial root $\gamma=0$ (discarded). With the minus sign, the above equation is reformulated as

$$
\begin{gathered}
(2+\mu) \gamma^{4}-\left[(1+\mu) \theta \beta^{2}+2(1+\mu) \beta^{2}+2\right] \gamma^{2} \\
+\left(\mu \theta^{2} \beta^{2}+2 \mu \theta \beta^{2}+2 \theta+2\right) \beta^{2}=0 .
\end{gathered}
$$

This is a quadratic equation in $\gamma^{2}$ and has two positive roots of $\gamma$ (i.e., $\gamma_{\mathrm{P}}$ and $\gamma_{\mathrm{Q}}$ ), representing the horizontal coordinates of the fixed point $P$ and $Q$ in Figure 3. Thus, the dimensionless frequency ratios of the fixed points $P$ and $Q$ can be solved from equation (14) as

$$
\begin{aligned}
& \gamma_{\mathrm{P}}^{2}=\frac{1+\mu \theta \beta^{2}+\mu \beta^{2}+\theta \beta^{2}+\beta^{2}-\sqrt{\left(\mu^{2}+\theta^{2}+2 \mu+2 \theta+1\right) \beta^{4}-2(1+\theta) \beta^{2}+1}}{2+\mu}, \\
& \gamma_{\mathrm{Q}}^{2}=\frac{1+\mu \theta \beta^{2}+\mu \beta^{2}+\theta \beta^{2}+\beta^{2}+\sqrt{\left(\mu^{2}+\theta^{2}+2 \mu+2 \theta+1\right) \beta^{4}-2(1+\theta) \beta^{2}+1}}{2+\mu} .
\end{aligned}
$$




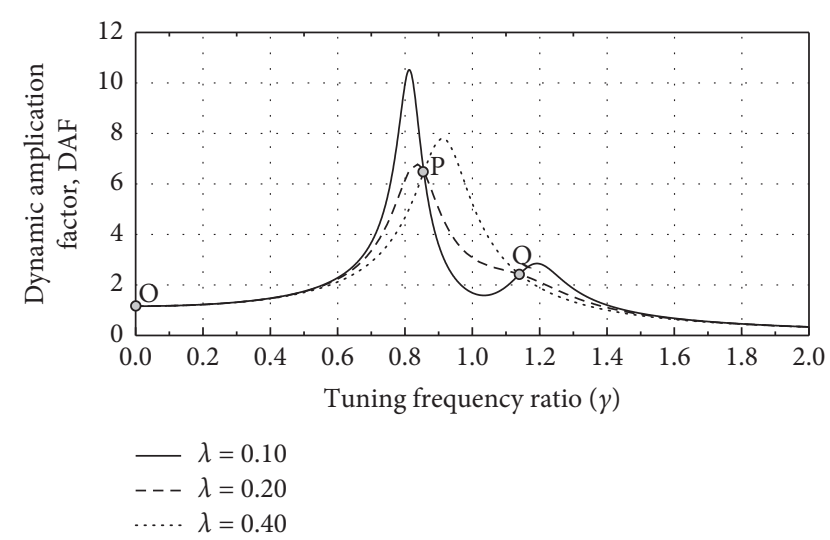

Figure 3: DAF curves of undamped primary system with $\mu=0.1$, $\beta=1.1$, and $\theta=-0.2$.

It is noted that $\gamma_{\mathrm{P}}$ and $\gamma_{\mathrm{Q}}$ are functions of $\mu, \beta$, and $\theta$. Thus, combining equation (15) and equation(16) gives

$$
\gamma_{\mathrm{P}}^{2}+\gamma_{\mathrm{Q}}^{2}=\frac{2\left(1+\mu \theta \beta^{2}+\mu \beta^{2}+\theta \beta^{2}+\beta^{2}\right)}{2+\mu} .
$$

Moreover, in the case of $\lambda=\infty$, adjusting the two fixed points to equal amplitudes gives

$$
\begin{aligned}
\left.\operatorname{DAF}\left(\gamma_{\mathrm{P}}\right)\right|_{\lambda=\infty} & =\left.\operatorname{DAF}\left(\gamma_{\mathrm{Q}}\right)\right|_{\lambda=\infty} \Rightarrow \frac{1}{1+\mu \theta \beta^{2}-(1+\mu) \gamma_{\mathrm{P}}^{2}} \\
& =-\frac{1}{1+\mu \theta \beta^{2}-(1+\mu) \gamma_{\mathrm{Q}}^{2}},
\end{aligned}
$$

where the minus sign is added because the horizontal coordinates of the two fixed points, $\gamma_{\mathrm{P}}$ and $\gamma_{\mathrm{Q}}$, are on different sides of the point of infinity. Manipulating equation (18) yields

$$
\gamma_{P}^{2}+\gamma_{Q}^{2}=\frac{2 \mu \theta \beta^{2}+2}{1+\mu}
$$

From equation (17) and equation (18), the optimum tuning frequency ratio is obtained as

$$
\beta_{\mathrm{opt}}=\sqrt{\frac{1}{(1+\mu)^{2}+\theta}} .
$$

This is the formula of the optimum tuning frequency ratio in terms of mass ratio $\mu$ and negative stiffness ratio $\theta$. The dimensionless frequency ratios of the fixed points $P$ and $Q$ under this condition are determined by

$$
\begin{aligned}
\gamma_{\mathrm{P}}^{2} & =\frac{1+\mu+\theta-(1+\mu) \sqrt{\mu /(2+\mu)}}{(1+\mu)^{2}+\theta}, \\
\gamma_{\mathrm{Q}}^{2} & =\frac{2(1+\mu+\theta)-\mu \theta+(1+\mu) \sqrt{2 \mu}}{2(1+\mu)^{2}+(2-\mu) \theta} .
\end{aligned}
$$

Under the condition of the optimum tuning frequency ratio $\beta_{\text {opt }}$, substituting equation (21) and equation (22) into equation (5) yields the vertical coordinates of the fixed points $P$ and $Q$.

$$
\operatorname{DAF}\left(\gamma_{P}\right)=\operatorname{DAF}\left(\gamma_{Q}\right)=\frac{(1+\mu)^{2}+\theta}{(1+\mu)^{2}} \sqrt{\frac{2+\mu}{\mu}} .
$$

According to the fixed points theory [1], the DAF at fixed point $P$ or $Q$ defined by equation (22) could be approximately taken as the maximum $\mathrm{DAF}\left(\mathrm{DAF}_{\max }\right)$ of the primary system with TID_NSD. After the optimum tuning frequency ratio $\beta_{\text {opt }}$ has been deduced, the subsequent step should be to determine the optimum damping ratio, which makes fixed points $P$ and $Q$ to be the maximum points on the DAF curve. The condition of fixed points $P$ and $Q$ being the maximum means that the response curve should pass through the two fixed points with a horizontal tangent; that is,

$$
\frac{\partial}{\partial \Gamma}|\operatorname{DAF}(\Gamma)|^{2}=0
$$
(6),

By clearing the denominator of the right side of equation

$$
A+B \lambda^{2}=\left(C+D \lambda^{2}\right) \cdot|\operatorname{DAF}(\Gamma)|^{2}
$$

By differentiating this equation with respect to $\Gamma$ and considering the condition $\partial|\operatorname{DAF}(\Gamma)|^{2} / \partial \Gamma=0$, the subsequent equation is derived as

$$
(\partial A / \partial \Gamma)+\lambda^{2} \cdot(\partial B / \partial \Gamma)=\left((\partial C / \partial \Gamma)+\lambda^{2} \cdot(\partial D / \partial \Gamma)\right) \cdot|\operatorname{DAF}(\Gamma)|^{2},
$$

where

$$
\begin{aligned}
(\partial A / \partial \Gamma)= & 2 \Gamma-2(1+\theta) \beta^{2} \\
(\partial B / \partial \Gamma)= & 4 \lambda^{2} \beta^{2} \\
(\partial C / \partial \Gamma)= & 2\left[-\Gamma^{2}+\left(\mu \beta^{2}+\theta \beta^{2}+\beta^{2}+1\right) \Gamma-\left(1+\theta+\mu \beta^{2}\right) \beta^{2}\right] \\
& \cdot\left[(1+\mu+\theta) \beta^{2}-2 \Gamma+1\right], \\
(\partial D / \partial \Gamma)= & 4 \lambda^{2} \beta^{2}\left(1+\mu \theta \beta^{2}+\mu \Gamma+\Gamma\right)^{2}+8 \lambda^{2} \beta^{2} \Gamma \\
& \cdot\left(1+\mu \theta \beta^{2}+\mu \Gamma+\Gamma\right)(1+\mu),
\end{aligned}
$$

Solving equation (26) with respect to $\lambda$ yields

$$
\lambda^{2}=\frac{|\operatorname{DAF}(\Gamma)|^{2} \cdot(\partial C / \partial \Gamma)-(\partial A / \partial \Gamma)}{(\partial B / \partial \Gamma)-|\operatorname{DAF}(\Gamma)|^{2} \cdot(\partial D / \partial \Gamma)} .
$$

The optimum damping ratio $\lambda_{\mathrm{P}}$ corresponding to the fixed point $\mathrm{P}$ is obtained by substituting equation (21), equation (22), and equation (23) into equation (27):

$$
\lambda_{\mathrm{P}}^{2}=\frac{[2+3 \mu-\sqrt{\mu(2+\mu)}] \mu}{4[(2+\mu)(1+\mu+\theta)+(1+\mu) \sqrt{\mu(2+\mu)}]} .
$$

Similarly, the optimum damping ratio $\lambda_{\mathrm{Q}}$ corresponding to the fixed point $Q$ is obtained as 


$$
\lambda_{\mathrm{Q}}^{2}=\frac{[2+3 \mu-\sqrt{\mu(2+\mu)}] \mu}{4[(2+\mu)(1+\mu+\theta)+(1+\mu) \sqrt{\mu(2+\mu)}]} .
$$

According to Brock's definition of the optimum damping ratio [34], a simple formula for the optimum damping ratio for TID_NSD could be obtained as a function of the mass ratio $\mu$ and negative stiffness ratio $\theta$ :

$$
\lambda_{\text {opt }}=\sqrt{\frac{\lambda_{P}^{2}+\lambda_{Q}^{2}}{2}}=\frac{1}{2} \sqrt{\frac{\mu(3+3 \theta+3 \mu+2 \mu \theta)}{(2+\mu) \theta^{2}+2(1+\mu)(2+\mu) \theta+2(1+\mu)^{2}}} .
$$

However, there still exists an adjustable parameter in the mathematical expression for the optimum tuning frequency ratio and damping ratio, that is, the optimum negative stiffness ratio. Therefore, the final step is to determine the optimum negative stiffness ratio. As shown in Figure 3, besides fixed points $P$ and $Q$, which are nonzero-frequency points, there is another intersection point $O$, which is also independent of damping of the TID_NSD. Since the fixed point $O$ is zerofrequency point, substituting $\gamma=0$ into equation (17), the value of DAF at the fixed point $O$ is formulated as

$$
\operatorname{DAF}\left(\gamma_{\mathrm{O}}=0\right)=\left|\frac{1+\theta}{1+\theta+\mu \theta \beta^{2}}\right| \text {. }
$$

Thus, under the condition of the optimum tuning frequency ratio $\beta_{\text {opt }}$ defined by equation (20), the value of DAF at the fixed point $\mathrm{O}$ is obtained by substituting equation(20) into equation (32):

$$
\operatorname{DAF}\left(\gamma_{\mathrm{O}}=0\right)=\frac{(1+\mu+\theta)\left[(1+\mu)^{2}+\theta\right]}{\theta^{2}+(1+\mu)(2+\mu) \theta+(1+\mu)^{2}} .
$$

It is noted that DAF $\left(\gamma_{\mathrm{O}}=0\right)$ is a monotonically decreasing function with a negative stiffness ratio $\theta$ if the stability requirement is satisfied. Moreover, based on equation (23), $\mathrm{DAF}_{\text {max }}$ is a monotonically increasing function with negative stiffness ratio $\theta$. Thus, in order to find the optimum negative stiffness ratio of TID_NSD for undamped systems, a suitable choice of negative stiffness ratio $\theta$ could be determined, whereby all fixed points $P, Q$, and $O$ are adjusted to equal heights. Imposing equal DAFs on all three fixed points gives

$$
\frac{(1+\mu+\theta)\left[(1+\mu)^{2}+\theta\right]}{\theta^{2}+(1+\mu)(2+\mu) \theta+(1+\mu)^{2}}=\frac{(1+\mu)^{2}+\theta}{(1+\mu)^{2}} \sqrt{\frac{2+\mu}{\mu}}
$$

Solving equation (23), five possible roots for the negative stiffness ratio can be obtained as follows:

$$
\begin{aligned}
& \theta_{1}=-(1+\mu)^{2}, \\
& \theta_{2}=-(1+\mu)+(1+\mu) \sqrt{\mu /(2+\mu)}, \\
& \theta_{3}=-(1+\mu)-(1+\mu) \sqrt{\mu /(2+\mu)}, \\
& \theta_{4}=-(1+\mu)^{2}+(1+\mu) \sqrt{\mu(2+\mu)}, \\
& \theta_{5}=-(1+\mu)^{2}-(1+\mu) \sqrt{\mu(2+\mu)} .
\end{aligned}
$$

Among the five negative stiffness ratios, only negative stiffness ratio $\theta_{4}$ could meet the stability requirement. Therefore, the negative stiffness ratio $\theta_{4}$ should be considered as the optimum negative stiffness ratio of the TID_NSD, namely,

$$
\theta_{\mathrm{opt}}=\theta_{4}=-(1+\mu)^{2}+(1+\mu) \sqrt{\mu(2+\mu)} .
$$

\section{Parametric Analysis and Performance Evaluation}

In this part, a parametric analysis on the seismic response of the TID_NSD system is conducted. The effect of a negative stiffness ratio and inertance ratio on the control performance is analyzed in detail.

By setting $\theta=0$ in (20) and (31), it is observed that the optimum tuning frequency ratio $\beta_{\mathrm{opt}}$ and the optimum damping ratio $\lambda_{\text {opt }}$ of the TID system derived by Den Hartog [1] and Shen et al. in Case 1 [35] can be retrieved as follows:

$$
\begin{aligned}
& \beta_{\mathrm{opt}}(\theta=0)=\frac{1}{(1+\mu)}, \\
& \lambda_{\mathrm{opt}}(\theta=0)=\sqrt{\frac{3 \mu}{8(1+\mu)}} .
\end{aligned}
$$

Therefore, based on the above limit case of $\theta=0$, it could be easy to compare the TID_NSD system optimization results in this study against the recent TID system optimization proposed by Shen et al. [35]. Moreover, to assess the effectiveness of the optimally designed TID_NSD system, the time history analysis (THA) is conducted using 20 real earthquake records, previously developed by Somerville et al. [36]. The same earthquake records, as detailed in Table 1, were also used in [35].

The maximum displacement and the maximum absolute acceleration, which are the two main response indicators useful and have practical significance for design engineers, are selected to analyze the role of a negative stiffness device in vibration control performance. For this purpose, the results of time history analyses using the real earthquakes records presented in Table 1 are averaged to get the mean values of the maximum displacement and the maximum absolute acceleration (i.e., $a_{p}=\ddot{u}_{p}+a_{g}$ ). The optimum tuning frequency ratio $\beta_{\text {opt }}$, optimum damping ratio $\lambda_{\text {opt }}$, and optimum negative stiffness ratio $\theta$ of the TID_NSD system are calculated by using the derived formulas defined 
TABLE 1: Los Angeles earthquake records with a probability of exceedance of $10 \%$ in 50 years.

\begin{tabular}{|c|c|c|c|c|c|c|}
\hline Name & Record & Magnitude & Distance $(\mathrm{km})$ & Scale factor & Duration $(\mathrm{s})$ & $\operatorname{Pga}\left(\mathrm{m} / \mathrm{s}^{2}\right)$ \\
\hline LA01 & Imperial valley, 1940 , el centro & 6.9 & 10 & 2.01 & 53.46 & 4.52 \\
\hline LA02 & Imperial valley, 1940 , el centro & 6.9 & 10 & 2.01 & 53.46 & 6.63 \\
\hline LA03 & Imperial valley, 1979 , Array\#05 & 6.5 & 4.1 & 1.01 & 39.38 & 3.86 \\
\hline LA04 & Imperial valley, 1979 , Array\#05 & 6.5 & 4.1 & 1.01 & 39.38 & 4.79 \\
\hline LA05 & Imperial valley, 1979 , Array $\# 06$ & 6.5 & 1.2 & 0.84 & 39.08 & 2.96 \\
\hline LA06 & Imperial valley, 1979 , Array $\# 06$ & 6.5 & 1.2 & 0.84 & 39.08 & 2.30 \\
\hline LA07 & Landers, 1992, barstow & 7.3 & 36 & 3.2 & 79.98 & 4.13 \\
\hline LA08 & Landers, 1992, barstow & 7.3 & 36 & 3.2 & 79.98 & 4.17 \\
\hline LA09 & Landers, 1992, yermo & 7.3 & 25 & 2.17 & 79.98 & 5.10 \\
\hline LA10 & Landers, 1992, yermo & 7.3 & 25 & 2.17 & 79.98 & 3.53 \\
\hline LA11 & Loma prieta, 1989 , gilroy & 7 & 12 & 1.79 & 39.98 & 6.52 \\
\hline LA12 & Loma prieta, 1989 , gilroy & 7 & 12 & 1.79 & 39.98 & 9.51 \\
\hline LA13 & Northridge, 1994 , newhall & 6.7 & 6.7 & 1.03 & 59.98 & 6.65 \\
\hline LA14 & Northridge, 1994, newhall & 6.7 & 6.7 & 1.03 & 59.98 & 6.44 \\
\hline LA15 & Northridge, 1994 , rinaldi RS & 6.7 & 7.5 & 0.79 & 14.95 & 5.23 \\
\hline LA16 & Northridge, 1994, rinaldi RS & 6.7 & 7.5 & 0.79 & 14.95 & 5.69 \\
\hline LA17 & Northridge, 1994, sylmar & 6.7 & 6.4 & 0.99 & 59.98 & 5.58 \\
\hline LA18 & Northridge, 1994, sylmar & 6.7 & 6.4 & 0.99 & 59.98 & 8.01 \\
\hline LA19 & North palm springs, 1986 & 6 & 6.7 & 2.97 & 59.98 & 9.99 \\
\hline LA20 & North palm springs, 1986 & 6 & 6.7 & 2.97 & 59.98 & 9.68 \\
\hline
\end{tabular}

TABLE 2: The mean of maximum displacement and maximum absolute acceleration of the primary system subjected to the 20 ground motions.

\begin{tabular}{lccccc}
\hline Damping system & $\lambda_{\text {opt }}$ & $\beta_{\text {opt }}$ & $\theta$ & $u_{P}(\mathrm{~cm})$ & 15.12 \\
TID & 0.25 & 0.83 & 0 & 14.41 & \\
& 0.21 & 1.00 & -0.2 & 13.53 & 5.09 \\
\multirow{2}{*}{ TID_NSD } & 0.24 & 1.11 & -0.4 & 12.18 & 5.40 \\
& 0.29 & 1.28 & -0.6 & 9.86 & 3.75 \\
\hline
\end{tabular}

in (20), (31) and, (36), respectively. On the other hand, the corresponding optimal parameters of the TID system are calculated by setting $\theta=0$ in the design formulas derived in this study (i.e., (20), (31), and (36)). Moreover, the subsequent parameters are used in numerical analysis: the natural period of the primary system, $T_{\mathrm{P}}\left(=2 \pi / \omega_{\mathrm{P}}\right)=1.0 \mathrm{~s}$; the damping ratio of the primary system $\lambda_{\mathrm{P}}=5 \%$; and the inertance ratio $\mu=0.1$.

As illustrated in Table 2, the effect of the absolute value of negative stiffness ratio $\theta$ in reducing the displacement and the absolute acceleration of the primary system becomes more significant with the increase in the inertance ratio $\mu$. For instance, in the case $\theta=-0.8$, the mean value of the maximum displacement and the absolute acceleration is significantly suppressed by $35.52 \%$ and $34.81 \%$ on average compared with the case without a negative stiffness device (i.e., $\theta=0$ ). Figure 4 displays the acceleration time history of the selected earthquake ground record LA 16 used to evaluate the seismic response of TID and TID_NSD in this section.

Moreover, the time histories of the maximum displacement and absolute acceleration of the primary system are illustrated in Figure 5 when both the TID_NSD and the
TID systems are subjected to a selected earthquake record (LA16). The succeeding parameters have been adopted in the numerical analysis: $\mu=0.1, \beta_{\text {opt }}=1.41, \lambda_{\text {opt }}=0.36$, and $\theta_{\text {opt }}=-0.71$ for the TID_NSD system; $\mu=0.1, \beta_{\text {opt }}=0.83$, and $\lambda_{\text {opt }}=0.25$ for the TID system.

As shown in Figure 5(a), the maximum displacement of the TID system is $25.50 \mathrm{~cm}$, which is reduced to $18.96 \mathrm{~cm}$ in TID_NSD system, corresponding to a $25.65 \%$ reduction ratio. On the other hand, the maximum absolute acceleration of the primary system (Figure 5(b)) decreases from $10.35 \mathrm{~m} / \mathrm{s}^{2}$ to $7.80 \mathrm{~m} / \mathrm{s}^{2}$ when the TID_NSD system is used (24.64\% reduction ratio).

Based on the above analysis results, it is clear that the performance of the TID_NSD system is considerably improved by the adoption of the negative stiffness device.

According to the analytical and numerical study conducted by Shen et al. [35], it was revealed that the design of the TID system using the design formula (39) and (40) (denoted as Case 2) is more effective for seismic response mitigation compared not only to the design formulas in (37) and (38) (denoted as Case 1) but also to those proposed in the previous study by $\mathrm{Hu}$ et al. [37]. 


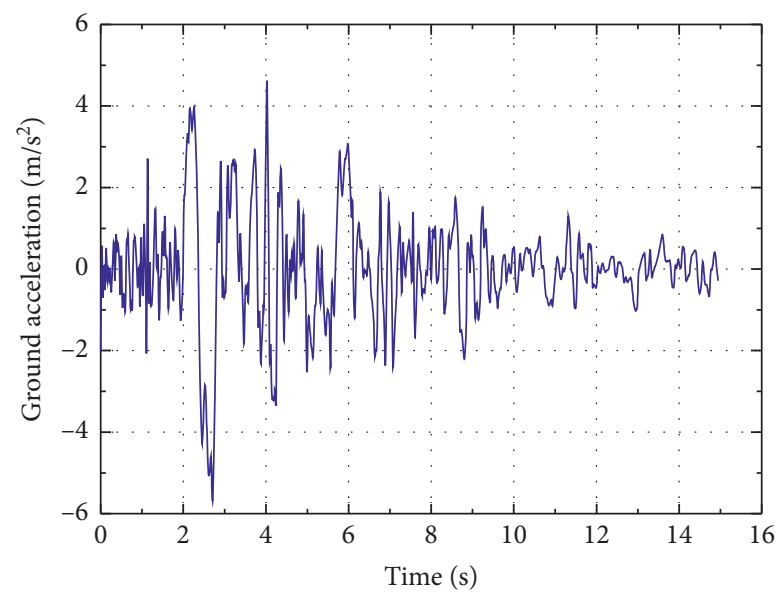

FIGURE 4: Ground acceleration time history of LA16 record.

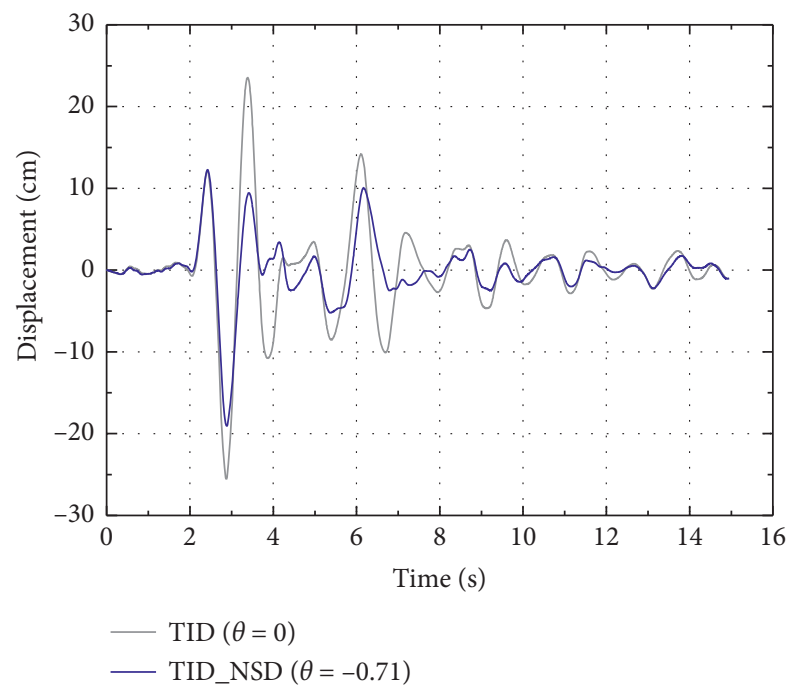

(a)

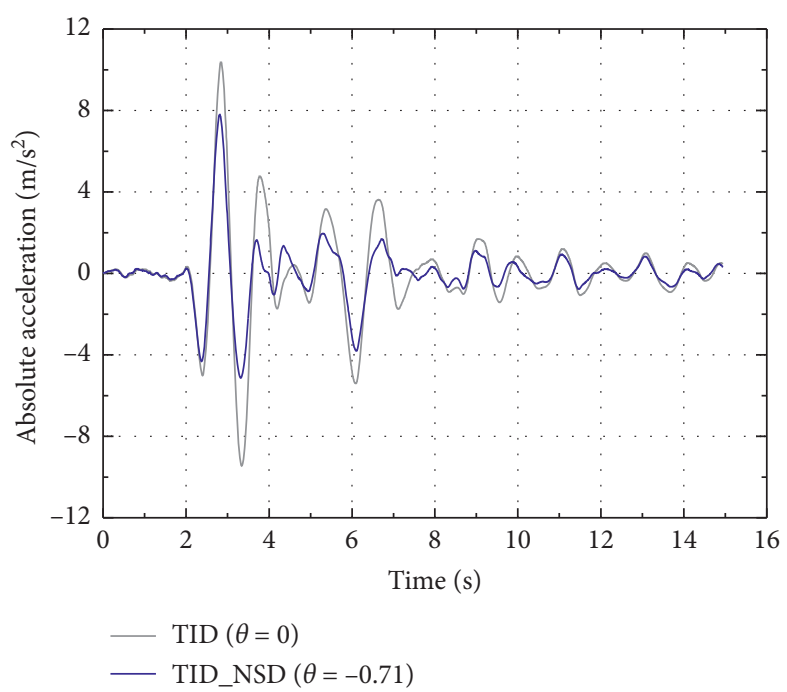

(b)

Figure 5: Time history response of the primary system under earthquake record LA16. (a) Maximum displacement. (b) Maximum absolute acceleration.

$$
\begin{aligned}
& \beta_{\mathrm{opt}}=\sqrt{\frac{1}{(1+\mu)}} \\
& \lambda_{\mathrm{opt}}=\sqrt{\frac{3 \mu}{4(2+\mu)}}
\end{aligned}
$$

Therefore, it is reasonable to compare the TID_NSD system results in this study and those of the TID system designed by using formulas of Case 2 in [35]. Also, it is worth presenting the results of the TID_NSD system for the limit case of $\theta=0$ to retrieve the results of the TID system corresponding to Case 1 .

The effect of the inertance ratio on the seismic response of the TID_NSD and TID systems is depicted in Figure 6. As shown in Figures 6(a) and 6(b), the mean value of the maximum displacement and absolute acceleration of both systems degrade with the increasing inertance ratio, indicating performance improvement. However, it is observed that the smaller the inertance ratio, the better the performance of the TID_NSD system. It should be noted that the improvement of the performance of the TID system with the increase in inertance ratio has been as well confirmed in the previous study by Shen et al. [35].

To further verify the vibration control effect of the TID_NSD and TID systems under optimal parameters, dynamic THA is conducted using a real earthquake signal corresponding to the LA16 earthquake record. Three inertance ratios, namely, $\mu=0.45,1.0$, and 2.5 , are employed to investigate the vibration control effect. As presented in Table 3, it is observed that setting the value of $\theta=0$ in the design formulas of the TID_NSD system yield approximately the same results as those of the TID system designed using the formulas in Case 1. Moreover, 


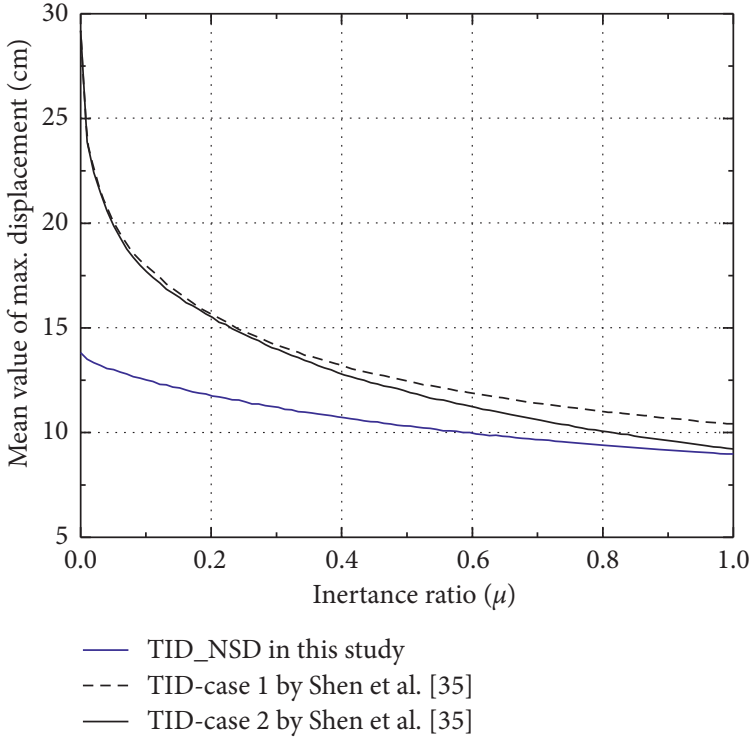

(a)

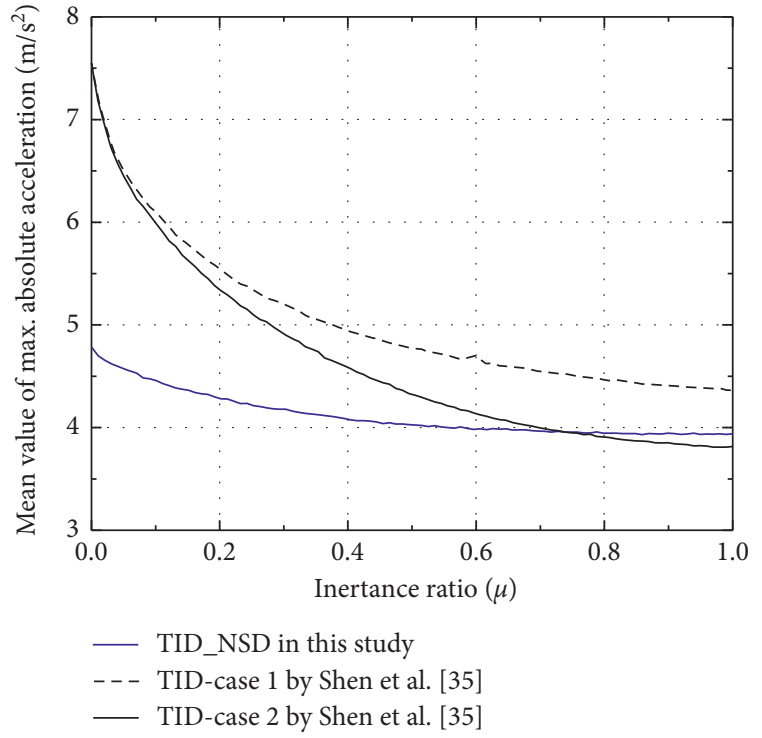

(b)

FIGURE 6: Effect of inertance ratio $\mu$ on the response of the TID_NSD system under 20 earthquake records. (a) Mean displacement. (b) Mean absolute acceleration.

TABle 3: Maximum displacement response and absolute acceleration of the primary system under earthquake record LA16.

\begin{tabular}{|c|c|c|c|c|c|c|c|}
\hline Damping system & Design method & $\mathrm{M}$ & $\lambda_{\text {opt }}$ & $\beta_{\text {opt }}$ & $\theta_{\text {opt }}$ & $u_{P}(\mathrm{~cm})$ & $a_{P}\left(\mathrm{~m} / \mathrm{s}^{2}\right)$ \\
\hline \multirow{2}{*}{ TID } & Shen et al. (Case 1) & \multirow{4}{*}{0.45} & 0.34 & 0.69 & - & 20.02 & 8.54 \\
\hline & Shen et al. (Case 2) & & 0.37 & 0.83 & - & 18.68 & 7.66 \\
\hline \multirow{2}{*}{ TID_NSD } & This study & & 0.34 & 0.69 & - & 19.98 & 8.52 \\
\hline & This study & & 0.51 & 0.81 & -0.58 & 16.01 & 7.00 \\
\hline \multirow{2}{*}{ TID } & Shen et al.(Case 1) & \multirow{4}{*}{1.00} & 0.43 & 0.50 & - & 16.41 & 7.56 \\
\hline & Shen et al.(Case 2) & & 0.5 & 0.71 & - & 13.61 & 6.14 \\
\hline \multirow{2}{*}{ TID_NSD } & This study & & 0.43 & 0.50 & - & 16.39 & 7.56 \\
\hline & This study & & 0.58 & 0.54 & -0.54 & 13.78 & 6.59 \\
\hline \multirow{2}{*}{ TID } & Shen et al. (Case 1) & \multirow{4}{*}{2.5} & 0.52 & 0.29 & - & 13.05 & 6.86 \\
\hline & Shen et al. (Case 2) & & 0.65 & 0.54 & - & 7.83 & 5.25 \\
\hline \multirow{2}{*}{ TID_NSD } & This study & & 0.52 & 0.29 & - & 13.01 & 6.85 \\
\hline & This study & & 0.65 & 0.29 & -0.51 & 11.38 & 6.31 \\
\hline
\end{tabular}

it is demonstrated that the response of the primary system for both systems decreases with increasing inertance. When a small inertance ratio is considered (i.e., $\mu=0.45$ ), the TID_NSD system outperforms the TID system in terms of both the displacement and the absolute acceleration control for both cases (i.e., Case 1 and Case 2), suggesting the same conclusion obtained in Figure 6. On the contrary, when a large inertance ratio is considered (i.e., $\mu>1.00$ ), the results indicate that the TID system provides better performance than the TID_NSD system.

From the numerical analysis presented in this section, it can be concluded that the negative stiffness device plays a vital role in response control of the TID_NSD system. It is also demonstrated that the proposed optimal design formulas of the proposed system are effective for seismic response mitigation.

\section{Installation of the TID_NSD System in a Case Study Building}

In this section, a numerical application is given to confirm the effectiveness of the proposed analytical design formulas of the TID-NSD system when dealing with the design problem of the multistory building. As shown in Figure 7, a TID_NSD system is installed at the bottom story of a case study building. The building's frame shown in Figure 7 represents the short direction plan of the Kajima Shizuoka steel structure in Japan [38]. The same building was also employed to study the TID system in [35].

The story heights, lumped story masses, and the lateral stiffnesses for the short side direction of the building are displayed in Table 4. The damping coefficients of the superstructure are determined by assuming Rayleigh damping such that the first two damping ratios are equal to $2 \%$. By using the 


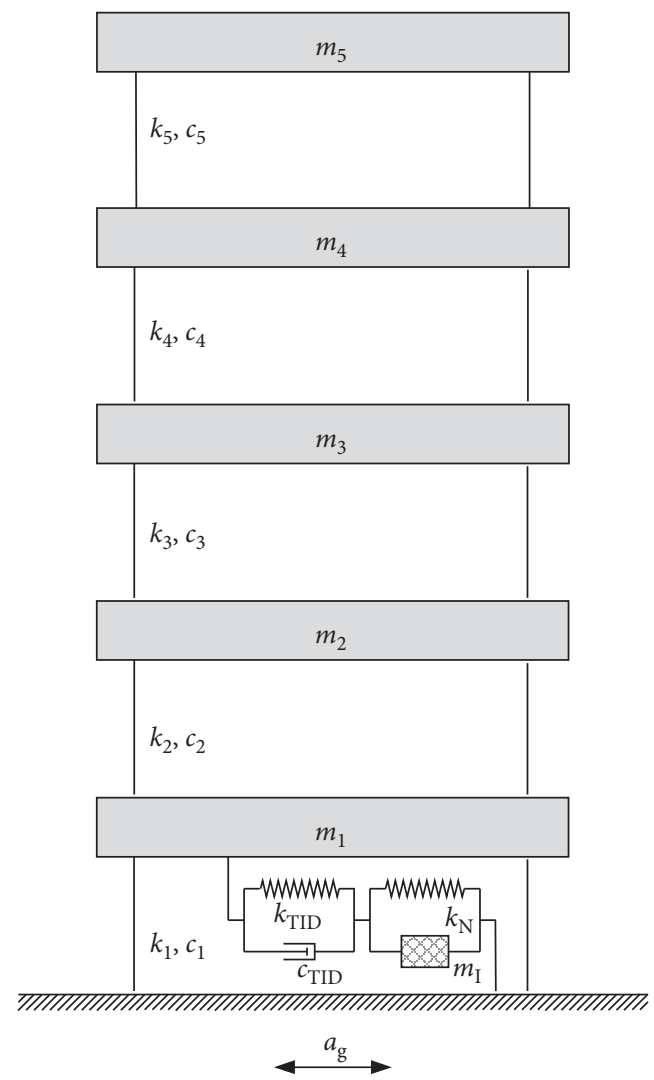

FIgURE 7: Mechanical model of the 5-storey frame building with TID_NSD system installed at the ground floor.

TABLE 4: Structural parameters of the case study building.

\begin{tabular}{llcccc}
\hline \multirow{2}{*}{ Story } & \multicolumn{2}{c}{ Height $(\mathrm{m})$} & Mass $\left(10^{3} \mathrm{~kg}\right)$ & Damping $\left(10^{3} \mathrm{kN} \cdot \mathrm{s} / \mathrm{m}\right)$ & $c_{\mathrm{i}}$ \\
\hline $5^{\text {th }}$ floor & $\mathrm{i}$ & $h_{\mathrm{i}}$ & $m_{\mathrm{i}}$ & $c_{\mathrm{i}}$ & 84 \\
$4^{\text {th }}$ floor & 5 & 3.6 & 266.1 & $c_{4}$ & 89 \\
$3^{\text {rd }}$ floor & 4 & 3.6 & 204.8 & $c_{3}$ & 99 \\
$2^{\text {nd }}$ floor & 3 & 3.6 & 207.0 & $c_{2}$ & 113 \\
$1^{\text {st }}$ floor & 2 & 3.6 & 209.2 & $c_{1}$ & 147 \\
\hline
\end{tabular}

classical modal analysis, the five natural periods of the building in the short side direction are calculated as [0.992, 0.354, 0.223, 0.173 , and 0.148$]$. Besides, the first mode shape is determined as [-0.0082,-0.0183,-0.0283,-0.0368,-0.0421].

The optimal design formulas derived previously for the SDOF structure can be appropriate for the MDOF structure shown in Figure 7, provided that the MDOF structure is simplified to an equivalent SDOF system characterized by the equivalent mass $\left(m_{\mathrm{e}}\right)$ and the equivalent stiffness $\left(k_{\mathrm{e}}\right)$. The equivalent mass $\left(m_{\mathrm{e}}\right)$ and the equivalent stiffness $\left(k_{\mathrm{e}}\right)$ can be calculated by using modal transformation given the condition that the period and damping ratio of the MDOF structure are, respectively, equal to the equivalent period and equivalent damping ratio of the SDOF structure. Furthermore, in line with other research works relevant to the design of the TID systems (see, e.g., literature [17]), the equivalent mass and the equivalent stiffness $\left(k_{\mathrm{e}}\right)$ are determined, while targeting the first mode of vibration.
In this numerical application, an inertance ratio $\mu$ is given as 0.2 , while the equivalent mass is calculated as $912.8 \times 10^{3}$ yielding an inertance $m_{\mathrm{I}}=m_{\mathrm{e}} \times$ $\mu=182.56 \times 10^{3} \mathrm{~kg}$. Consequently, the optimal design parameters of the TID_NSD system are determined as $k_{\mathrm{TID}}=9.203 \times 10^{3} \mathrm{kN} / \mathrm{m}^{2}, \quad C_{\mathrm{TID}}=1.099 \times 10^{3}, \quad \mathrm{kNs} / \mathrm{m}$, $\theta=-0.644$, and $k_{\mathrm{N}}=-5.927 \times 10^{3} \mathrm{kN} / \mathrm{m}^{2}$. For the practical implementation of the TID_NSD system, practical acceptable inerter's size, negative stiffness device's size, and damping values should be within a reasonable limit. Taking an inerter with a ball-screw mechanism as an example, the inertance $m_{\mathrm{I}}$ can be achieved by

$$
m_{I}=\left(\frac{2 \pi}{P}\right)^{2} J
$$

in which $P$ is the pitch of the inerter assembly, and $J$ represents the flywheel's moment of inertia. For instance, if the 


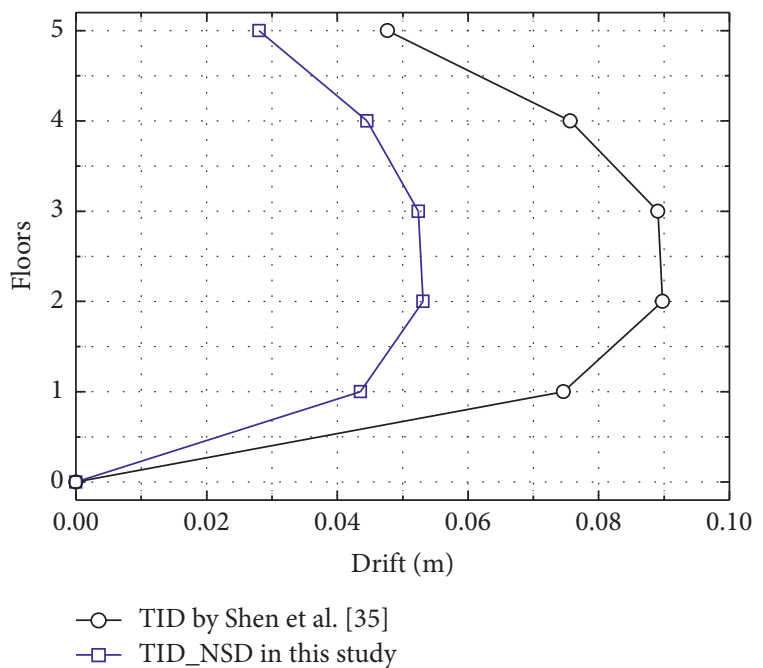

(a)

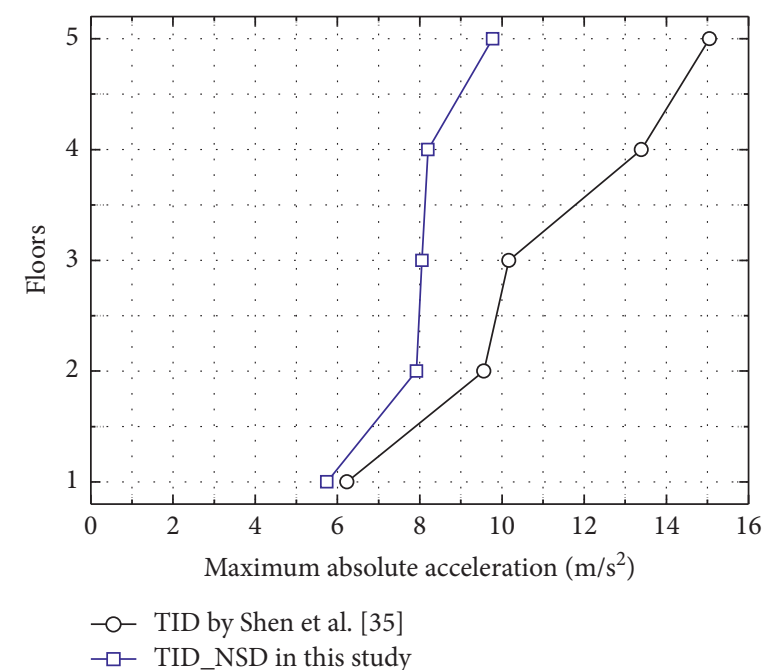

(b)

FIGURE 8: Maximum absolute interstorey drifts and absolute accelerations of the case study building subjected to LA04 earthquake record.

value of the pitch is fixed, to achieve the amount of inertance $m_{\mathrm{I}}=182.56 \times 10^{3} \mathrm{~kg}$ in this application, the moment of inertia $J$ of the flywheel can be determined from (41). By using the calculated value of the moment of inertia $J$, the physical dimensions of the flywheel can be computed, with which the physical ball-screw inerter type can be designed and realized. This method has been used for realizing and applying the TVMD to a 14-storey structure in Sendai, Japan [39]. It is worth noting that an inerter can be designed to produce an inertance thousands of times higher than its physical mass [15]. It can be pointed out that the numerical values obtained in this application are within acceptable technological capabilities and therefore render the implementation of the TID_NSD system feasible.

The seismic responses of the 5-storey building with the TID-NSD system and TID system are calculated by linear THA using the earthquake ground motions previously employed (i.e., LA01-LA20). The results of these 20 ground motions are then averaged to get the mean maximum absolute displacements and mean maximum absolute accelerations. For comparison, the same structure shown in Figure 7 without a negative stiffness device (i.e., TID system) is employed. For the considered earthquake motions, the findings show that the average maximum absolute displacement at the roof level is reduced from $0.7967 \mathrm{~m}$ of the TID system to $0.4202 \mathrm{~m}$ of the TID_NSD system, corresponding to roughly $38.30 \%$ decrease. Regarding the acceleration performance, the results indicate that the absolute acceleration at the roof is decreased from $26.36 \mathrm{~m} / \mathrm{s}^{2}$ to $16.45 \mathrm{~m} / \mathrm{s}^{2}$ (37.60\% reduction) in a TID_NSD system.

Moreover, Figure 8 depicts the results of THA for the selected earthquake motion (i.e., LA04) to illustrate the peak interstorey drifts and the variation of the absolute floor accelerations across the building height. It can be observed that the TID_NSD system achieves an excellent level of response control compared to the TID system. In particular, the interstorey drifts and the floor accelerations are significantly reduced. Figure 8 depicts the results of THA for the selected earthquake motion (i.e., LA04) to illustrate the peak interstorey drifts and the variation of the absolute floor accelerations across the building height. It can be observed that the TID_NSD system achieves an excellent level of response control compared to the TID system. In particular, the interstorey drifts and the floor accelerations are significantly reduced.

The THA results in this section suggest that the derived design formulas in this study are effective for seismic response control of a practical MDOF structure subjected to real earthquake records.

\section{Conclusions}

The TID_NSD is presented in this study and investigated in detail. The optimum parameters of the TID_NSD are analytically derived in terms of $\mathrm{H}_{\infty}$ norm when the primary undamped system is subjected to harmonic support excitation. The investigation shows that there are three fixed points (two nonzero-frequency fixed points plus one zerofrequency fixed point), all independent of the damping of TID_NSD in the DAF curve of the primary system. In terms of the two nonzero-frequency fixed points, the optimum tuning frequency $\beta_{\text {opt }}$ and optimum damping ratio $\lambda_{\text {opt }}$ for the TID_NSD are obtained based on the fixed points theory. Based on the definition of $\mathrm{H}_{\infty}$ optimization, by imposing the zero-frequency fixed point having the same height as the two nonzero-frequency fixed points, the optimum negative stiffness ratio $\theta_{\text {opt }}$, which make the whole system with the TID_NSD remain stable at the same time, is obtained.

Moreover, a parametric study has been carried out to examine the role of a negative stiffness device on the control performance of the TID_NSD system. It has been indicated that the proposed optimal design formulas of the TID_NSD are effective for seismic response mitigation of both SDOF structure and MDOF structure. At the same time, numerical results demonstrate that the TID_NSD outperforms the TID in terms of displacement and absolute acceleration control. 
This study contributes to the analytical optimal design formulas of the structure equipped with TID_NSD and gives insight into the beneficial features of the TID_NSD in terms of the vibration mitigation performance.

\section{Data Availability}

The data used to support the findings of this study are available from the corresponding author upon request.

\section{Conflicts of Interest}

The authors declare that there are no conflicts of interest regarding the publication of this paper.

\section{Acknowledgments}

This work was supported by the National Natural Science Foundation of China (Grant no. 52078234).

\section{References}

[1] J. P. DenHartog, Mechanical Vibrations, Dover Publications Inc, Mineola, New York, USA, 1985.

[2] M. C. Smith, "Synthesis of mechanical networks: the inerter," in Proceedings of the 41st IEEE Conference on Decision and Control, Las Vegas, Nevada, USA, December 2002.

[3] M. Chen, C. Papageorgiou, F. Scheibe, F.-c. Wang, and M. Smith, "The missing mechanical circuit element," IEEE Circuits and Systems Magazine, vol. 9, no. 1, pp. 10-26, 2009.

[4] Y. Hu, M. Z. Q. Chen, and Z. Shu, "Passive vehicle suspensions employing inerters with multiple performance requirements," Journal of Sound and Vibration, vol. 333, no. 8, pp. 2212-2225, 2014.

[5] M. C. Smith and F.-C. Wang, "Performance benefits in passive vehicle suspensions employing inerters," Vehicle System Dynamics, vol. 42, no. 4, pp. 235-257, 2004.

[6] F.-C. Wang and H.-A. Chan, "Vehicle suspensions with a mechatronic network strut," Vehicle System Dynamics, vol. 49, no. 5, pp. 811-830, 2011.

[7] S. Evangelou, D. J. N. Limebeer, R. S. Sharp, and M. C. Smith, "Control of motorcycle steering instabilities," IEEE Control Systems Magazine, vol. 26, no. 5, pp. 78-88, 2006.

[8] F.-C. Wang, M.-R. Hsieh, and H.-J. Chen, "Stability and performance analysis of a full-train system with inerters," Vehicle System Dynamics, vol. 50, no. 4, pp. 545-571, 2012.

[9] F.-C. Wang, M.-K. Liao, B.-H. Liao, W.-J. Su, and H.-A. Chan, "The performance improvements of train suspension systems with mechanical networks employing inerters," Vehicle System Dynamics, vol. 47, no. 7, pp. 805-830, 2009.

[10] C. Papageorgiou, N. E. Houghton, and M. C. Smith, "Experimental testing and analysis of inerter devices," Journal of Dynamic Systems, Measurement and Control, Transactions of the ASME, vol. 131, no. 1, pp. 1-11, 2009.

[11] A. Gonzalez-Buelga, L. R. Clare, S. A. Neild, J. Z. Jiang, and D. J. Inman, "An electromagnetic inerter-based vibration suppression device," Smart Materials and Structures, vol. 24, no. 5, Article ID 055015, 2015.

[12] S. J. Swift, M. C. Smith, A. R. Glover, C. Papageorgiou, B. Gartner, and N. E. Houghton, "Design and modelling of a fluid inerter," International Journal of Control, vol. 86, no. 11, pp. 2035-2051, 2013.
[13] D. De Domenico, H. Qiao, Q. Wang, Z. Zhu, and G. Marano, "Optimal design and seismic performance of Multi-Tuned Mass Damper Inerter (MTMDI) applied to adjacent high-rise buildings," The Structural Design of Tall and Special Buildings, vol. 29, no. 14, Article ID e1781, 2020.

[14] C. Málaga-Chuquitaype, C. Menendez-Vicente, and R. Thiers-Moggia, "Experimental and numerical assessment of the seismic response of steel structures with clutched inerters," Soil Dynamics and Earthquake Engineering, vol. 121, pp. 200-211, 2019.

[15] K. Ikago, K. Saito, and N. Inoue, "Seismic control of singledegree-of-freedom structure using tuned viscous mass damper," Earthquake Engineering \& Structural Dynamics, vol. 41, no. 3, pp. 453-474, 2012.

[16] K. Ikago, Y. Sugimura, K. Saito, and N. Inoue, "Modal response characteristics of a multiple-degree-of-freedom structure incorporated with tuned viscous mass dampers," Journal of Asian Architecture and Building Engineering, vol. 11, no. 2, pp. 375-382, 2012.

[17] I. F. Lazar, S. A. Neild, and D. J. Wagg, "Using an inerterbased device for structural vibration suppression," Earthquake Engineering \& Structural Dynamics, vol. 43, no. 8, pp. 1129-1147, 2014.

[18] L. Marian and A. Giaralis, "Optimal design of a novel tuned mass-damper-inerter (TMDI) passive vibration control configuration for stochastically support-excited structural systems," Probabilistic Engineering Mechanics, vol. 38, pp. 156-164, 2014.

[19] D. Pietrosanti, M. De Angelis, and M. Basili, "Optimal design and performance evaluation of systems with tuned mass damper inerter (TMDI)," Earthquake Engineering \& Structural Dynamics, vol. 46, no. 8, pp. 1367-1388, 2017.

[20] D. De Domenico and G. Ricciardi, "An enhanced base isolation system equipped with optimal tuned mass damper inerter (TMDI)," Earthquake Engineering \& Structural Dynamics, vol. 47, no. 5, pp. 1169-1192, 2018.

[21] D. De Domenico, G. Ricciardi, and R. Zhang, "Optimal design and seismic performance of tuned fluid inerter applied to structures with friction pendulum isolators," Soil Dynamics and Earthquake Engineering, vol. 132, Article ID 106099, 2020.

[22] I. Antoniadis, D. Chronopoulos, V. Spitas, and D. Koulocheris, "Hyper-damping properties of a stiff and stable linear oscillator with a negative stiffness element," Journal of Sound and Vibration, vol. 346, pp. 37-52, 2015.

[23] D. T. R. Pasala, A. A. Sarlis, S. Nagarajaiah, A. M. Reinhorn, M. C. Constantinou, and D. Taylor, "Adaptive negative stiffness: new structural modification approach for seismic protection," Journal of Structural Engineering, vol. 139, no. 7, pp. 1112-1123, 2013.

[24] A. Saha and S. K. Mishra, "Adaptive Negative Stiffness Device based nonconventional Tuned Mass Damper for seismic vibration control of tall buildings," Soil Dynamics and Earthquake Engineering, vol. 126, Article ID 105767, 2019.

[25] A. A. Sarlis, D. T. R. Pasala, M. C. Constantinou, A. M. Reinhorn, S. Nagarajaiah, and D. P. Taylor, "Negative stiffness device for seismic protection of structures," Journal of Structural Engineering, vol. 139, no. 7, pp. 1124-1133, 2013.

[26] X. Shi and S. Zhu, "A comparative study of vibration isolation performance using negative stiffness and inerter dampers," Journal of the Franklin Institute, vol. 356, no. 14, pp. 79227946, 2019.

[27] M. S. Trimboli, R. Wimmel, and E. Breitbach, "A quasi-active approach to vibration isolation using magnetic springs," 
Smart Structures and Materials 1994: Passive Damping, vol. 2193pp. 73-83, USA, 1994.

[28] M. Wang, F.-f. Sun, J.-q. Yang, and S. Nagarajaiah, "Seismic protection of SDOF systems with a negative stiffness amplifying damper," Engineering Structures, vol. 190, pp. 128141, 2019.

[29] X. Wang, T. He, Y. Shen, Y. Shan, and X. Liu, "Parameters optimization and performance evaluation for the novel inerter-based dynamic vibration absorbers with negative stiffness," Journal of Sound and Vibration, vol. 463, Article ID 114941, 2019.

[30] Y. C. Wang and R. S. Lakes, "Extreme stiffness systems due to negative stiffness elements," American Journal of Physics, vol. 72, no. 1, pp. 40-50, 2004.

[31] J. Zhou, Q. Xiao, D. Xu, H. Ouyang, and Y. Li, "A novel quasizero-stiffness strut and its applications in six-degree-of-freedom vibration isolation platform," Journal of Sound and Vibration, vol. 394, pp. 59-74, 2017.

[32] S. Zhou, C. Jean-Mistral, and S. Chesne, "Closed-form solutions to optimal parameters of dynamic vibration absorbers with negative stiffness under harmonic and transient excitation," International Journal of Mechanical Sciences, vol. 157158, pp. 528-541, 2019.

[33] H.-N. Li, C. Qu, L. Huo, and S. Nagarajaiah, "Equivalent bilinear elastic single degree of freedom system of multidegree of freedom structure with negative stiffness," Journal of Sound and Vibration, vol. 365, pp. 1-14, 2016.

[34] J. E. Brock, "A note on the damped vibration absorber," Journal of Applied Mechanics, vol. 13284 pages, 1946.

[35] W. Shen, A. Niyitangamahoro, Z. Feng, and H. Zhu, "Tuned inerter dampers for civil structures subjected to earthquake ground motions: optimum design and seismic performance," Engineering Structures, vol. 198, Article ID 109470, 2019.

[36] P. Somerville, N. Smith, S. Punyamurthula, and J. Sun, Development Of Ground Motion Time Histories For Phase II Of the FEMA/SAC Steel Project. SAC Background Document Report, Report No. SAC/BD-97/04, SAC Joint Venture, Sacramento, CA, USA, 1997.

[37] Y. Hu, M. Z. Q. Chen, Z. Shu, and L. Huang, "Analysis and optimisation for inerter-based isolators via fixed-point theory and algebraic solution," Journal of Sound and Vibration, vol. 346, pp. 17-36, 2015.

[38] N. Kurata, T. Kobori, M. Takahashi, N. Niwa, and H. Midorikawa, "Actual seismic response controlled building with semi-active damper system," Earthquake Engineering \& Structural Dynamics, vol. 28, no. 11, pp. 1427-1447, 1999.

[39] Z. Chen, K. Junya, I. Masahiro, I. Kohju, and I. Norio, "Viscoelastically supported viscous mass damper incorporated into a seismic isolation system," Journal of Earthquake and Tsunami, vol. 10, no. 03, Article ID 1640009, 2016. 